\title{
Comparison of Epicardial Adipose Tissue Fatty Hcid Profile in Cardiovascular Disease Patients Diabetic and Non-Diabetic
}

\author{
Seyyed Manuchehr Nourazarian \\ (PhD) \\ Department of Laboratory Sciences, \\ Faculty of Paramedicine, Tabriz \\ University of Medical Sciences, \\ Tabriz, Iran
}

Mojtaba Ghaffarian (MSc)

Department of Molecular Biology,

Islamic Azad University, Ahar Branch,

Ahar, Iran

Homayun Dolatkhah $(\mathrm{PhD})$

Department of Clinical Biochemistry and Laboratoris Medicine, Faculty of

Medicine, Tabriz University of

Medical Sciences, Tabriz, Iran

Corresponding Author: Homayun

Dolatkhah

Email: dolatkhahh@gmail.com

Tel: +989143117197

Adderess: Golestan University of

Medical Sciences, Gorgan, Iran

Received : 06 Oct 2014

Revised: 08 Nov 2014

Accepted: 12 Nov 2014

\section{ABSTRACT}

Background and Objective: The relationship between diabetes mellitus and increased risk of cardiovascular diseases has been demonstrated. The aim of this study was to determine the fatty acid profile of epicardial adipose tissue in diabetic and non-diabetic patients with cardiovascular disease.

Methods: In this study, 28 diabetic and 40 nondiabetic patients were evaluated. The epicardial adipose tissue and blood samples of patients were collected during surgery. Nonesterified fatty acids and phospholipids were measured by the thin layer chromatography and gas chromatography.

Results: Saturated free fatty acids (12: 0 ) level was higher in diabetic patients compared to nondiabetic patients $(\mathrm{P}=0.030)$, while saturated free fatty acids $(16: 0)$ was significantly lower in diabetics $(\mathrm{P}=0.011)$. Unsaturated fatty acid $(20$ : $3 \mathrm{n}-9)$ was higher in nondiabetics compared to diabetics $(\mathrm{P}=0.015)$. There was a significant decrease in level of monounsaturated fatty acids in diabetic patients. The epicardial adipose tissue of diabetics showed a significant increase in free fatty acid (10: 0) and conjugated linoleic acid levels, while there was a significant decrease in the level of free fatty acid (18: $1 n-11)$. Level of epicardial omega-3 free fatty acid (20: $5 \mathrm{n}-3)$ and 22: $6 \mathrm{n}-3$ was significantly reduced in these patients.

Conclusion: Differences in the serum free fatty acid profile of the two groups may be due to differences in their diet, while changes in the fatty acid composition of epicardial adipose tissue in these two groups could be due to impaired metabolism of fatty acids such as uptake, movement and androgen synthesis as a result of diabetes. These changes increase the risk of developing atherosclerosis in diabetic patients.

Keywords: Diabetes Mellitus, Adipose Tissue, Atherosclerosis, Cardiovascular Disease. 


\section{INTRODUCTION}

The association between type II diabetes mellitus and cardiovascular disease (CVD) has been well demonstrated (1). Nowadays, it is generally accepted that insulin resistance and decreased insulin secretion are the major causes of type II diabetes (2). It is also reported that high intake of glucose and fatty acids are the main causes of $\beta$-cells dysfunction (3). Although fatty acids increase insulin secretion, its chronic increase inhibits insulin secretion (4). This may be due to decreased oxidation of fatty acids and accumulation of long-chain fatty acids in hyperglycemia (5). The association between plasma fatty acids and CVD has attracted a lot of attention in recent years. PiLz et al. reported that the level of free fatty acid (FFA) in blood is an independent factor associated with sudden cardiac death (6). The relationship between the level of FFAs and metabolic syndrome such as diabetes, hypertension and obesity [Body Mass Index (BMI) > 30)], insulin resistance, triglyceride levels and Creactive protein (risk factors for cardiovascular disease) has been reported (7). In this regard, trans-fatty acids and Omega-3 fatty acids (such as eiscosa pentaenoic acid) have been emphasized as risk factor and protective compound for CVD, respectively (8). Recent studies have shown that epicardial fat is a major risk factor for heart disease (9). The secretion of inflammatory cytokines from this adipose tissue and its proximity with coronary arteries one hand, and the role of epicardial fat in developing the risk factors for CVD including blood pressure on the other, may explain the role of epicardial fat in coronary artery disease (10). Zhao et al. study on 203 patients with suspected coronary artery disease undergoing coronary angiography measured the diameter of fat by echocardiography and reported a specific correlation between the epicardial fat thickness, age and abdominal circumference with the severity of coronary artery disease (11). In Greulich study in 2012, the role of this fat in coronary artery disease has been proven (12). Despite the high prevalence of coronary artery disease in our country and the cost it causes in the society, no study has been performed to assess the role of epicardial fat in the risk of developing coronary arteries disease and its impact on acute coronary syndrome. Therefore, this study aimed to determine the fatty acid composition of epicardial adipose tissue in diabetic and non-diabetic CVD patients.

\section{MATERIAL AND METHODS}

This was a case-control study that was designed by considering similar previous studies at $95 \%$ confidence level for each group of 40 patients. The target population was diabetic patients who were candidates for open-heart surgery. Therefore, 40 non-diabetic patients and 28 diabetic patients with more than $75 \%$ stenosis of coronary arteries that were candidates for open heart surgery were enrolled in this study. All patients were admitted to the Shahid Madani Hospital in Tabriz. The research proposal was approved by the ethics committee of Tabriz University of Medical Sciences. The patients with high blood pressure and high cholesterol levels were excluded from the study. Selection and evaluation of diabetic patients were performed according to the World Health Organization criteria (13).Inclusion criteria: Diabetics with coronary artery stenosis of $>75 \%$ who were candidates for coronary artery bypass grafting (CABG) Exclusion criteria: Patients with high blood pressure; high blood cholesterol levels; high triacylglycerol. Fasting blood samples (5 $\mathrm{ml}$ ) were collected from each patient prior to surgery. Serums were obtained and kept in a freezer at $-70{ }^{\circ} \mathrm{C}$ until the start of relevant experiments. Epicardial and subcutaneous adipose tissue was collected during the surgery. Epicardial adipose tissue biopsies were obtained approximately from the proximal right coronary artery. The samples were dissolved in hexane and then stored in capped glass vials for less than three months at $-70{ }^{\circ} \mathrm{C}$ until the time of analysis. The concentration of fasting blood sugar (FBS), cholesterol, triglycerides, high-density lipoprotein (HDL) in the collected serums was examined using Pars Azmoon kit and autoanalyzer (Abbott Co.). Separation of nonesterified free fatty acids (NEFA) and phospholipids from the serum was performed according to the Bligh \& Dyer method (14).

Separation of fatty acids from adipose tissue The hexane in the vials containing epicardial and subcutaneous adipose tissue was vaporized using nitrogen gas and the content of adipose tissue were determined according to 
the method described by Lepage et al. (15). The results of gas chromatography separation were obtained in form of Chromatograms. In this method, the Buck Scientific 610 gas chromatograph and $6 \mathrm{~mm} \times 0.25 \mathrm{~mm}$ column (TR-CN100, Teknokroma Co.) were used. The written consent was obtained from all patients before the study. All the experiments were free and no cost was imposed on patients. The data was reported as mean \pm standard deviation (SD). Due to the small sample size, comparison of mean variables between the two groups was carried out using the nonparametric Kruskal-Wllis test. P-value of $\leq$ 0.05 was considered as the statistical significance level. All stages of data analysis were performed using SPSS software.

\section{RESULTS}

Demographic information of the diabetic and non-diabetic patients in this study is shown in Table 1. No significant difference was observed between the two test groups in relation to age, BMI, height, weight and smoking habit. The male to female ratio in the diabetic and non-diabetic groups of patients was 1.5 to 2 , respectively. Blood sugar levels $(\mathrm{P}=0.0001)$, glycosylated hemoglobin $(\mathrm{P}=$ $0.032)$, cholesterol $(\mathrm{P}=0.001)$ and triglyceride $(\mathrm{P}=0.0001)$ levels were significantly higher in the diabetic patients. However, there was no significant difference in the cholesterol, HDL and LDL levels between the two groups. Profile of FFAs and fractions of phospholipids of each group is summarized in Table 2. The percentage of saturated FFAs (12:0) in the fractions of FFAs of diabetic patients was higher than the non-diabetic patients $(\mathrm{P}=0.038)$, while the percentage of saturated FFAs (16:0) was significantly lower $(p=0.011)$. Meanwhile, the percentage of unsaturated FFAs 20:3n-9 in this fraction was higher in non-diabetic patients in comparison with the diabetics $(\mathrm{P}=0.015)$. Compared with the fractions of FFAs, fatty acids of phospholipid fraction had more differences within the two groups. In serum of diabetics, the percentage of 16:0 was significantly lower than non-diabetics $(\mathrm{P}=0.0001)$, while 18:0 was significantly higher $(\mathrm{P}=0.0001)$. Moreover, there was a significant reduction in the percentage of monounsaturated fatty acids (MUFA) of diabetic patients. Data analysis showed that this difference in the two groups was due to the low level of 18:0 $(\mathrm{P}=0.013)$. In relation to the amount of polyunsaturated fatty acids (PUFA), the percentage of 18:2n-6 $(\mathrm{P}=0.0001)$ and $18: 3 \mathrm{n}-9 \quad(\mathrm{P}=0.0001)$ was significantly lower in serum phospholipids fraction of diabetics when compared to nondiabetics.

Table 1- Basic characteristics of diabetic and non-diabetic candidates for CABG

\begin{tabular}{|c|c|c|c|}
\hline Variable & $\begin{array}{c}\text { Non-diabetic (40 patients) } \\
\text { Mean } \pm \text { SD }\end{array}$ & $\begin{array}{c}\text { Diabetic (28 patients) } \\
\text { Mean } \pm \text { SD }\end{array}$ & p-Value \\
\hline Age (years) & $54.6 \pm 6.9$ & $53.4 \pm 7.6$ & 0.102 \\
\hline Weight (Kg) & $76.2 \pm 11.3$ & $71.5 \pm 11.2$ & 0.133 \\
\hline Height $(\mathbf{C m})$ & $166.1 \pm 8.5$ & $160.4 \pm 8.6$ & 0.017 \\
\hline BMI $\left(\mathrm{kg} / \mathbf{m}^{2}\right)$ & $27.5 \pm 4.4$ & $27.7 \pm 4.0$ & 0.864 \\
\hline Male/Female ratio & 2 & 1.5 & 0.959 \\
\hline Smoker (\%) & 45 & 48 & 0.854 \\
\hline FBS (mg/dl) & $92.8 \pm 10.6$ & $148.0 \pm 36.4$ & 0.0001 \\
\hline Glycosylated hemoglobin (\%) & $4.0 \pm 0.5$ & $5.5 \pm 1.1$ & 0.032 \\
\hline Cholesterol (mg/dl) & $163.4 \pm 38.7$ & $195.1 \pm 41.0$ & 0.001 \\
\hline Triglycerides (mg/dl) & $97.3 \pm 23.6$ & $158.4 \pm 36.2$ & 0.0001 \\
\hline HDL (mg/dl) & $38.4 \pm 9.8$ & $36.1 \pm 6.8$ & 0.350 \\
\hline LDL (mg/dil) & $101.2 \pm 37.9$ & $116.0 \pm 47.6$ & 0.192 \\
\hline
\end{tabular}


16/ Comparison of Epicardial Adipose Tissue...

Table 2- Profile of serum FFAs, FFAs and phospholipids fraction in diabetic and non-diabetic patients

\begin{tabular}{cccc}
\hline Variable & $\begin{array}{c}\text { Non-diabetic (40 patients) } \\
\text { Mean } \pm \text { SD }\end{array}$ & $\begin{array}{c}\text { Diabetic (28 patients) } \\
\text { Mean } \pm \text { SD }\end{array}$ & p- Value \\
\hline NEFA & & & \\
Lauric acid (12:0) & $0.44 \pm 0.09$ & $0.68 \pm 0.10$ & 0.038 \\
Palmitic acid (16: 0) & $24.12 \pm 1.22$ & $28.50 \pm 3.15$ & 0.011 \\
Arachidonic acid 20:4n-6 & $0.39 \pm 0.07$ & $0.64 \pm 0.19$ & 0.015 \\
Phospholipids fraction & & & $<0.0001$ \\
Palmitic acid (16:0) & $25.01 \pm 1.58$ & $27.84 \pm 1.82$ & $<0.0001$ \\
Stearic acid (18:0) & $14.62 \pm 1.18$ & $13.15 \pm 1.24$ & 0.0135 \\
Oleic acid 18:1n-9 & $8.95 \pm 1.08$ & $8.13 \pm 1.24$ & 0.0003 \\
Linoleic acid 18:2n-6 & $20.25 \pm 2.45$ & $22.95 \pm 2.64$ & 0.0001 \\
Linoleic acid 18:3n-9 & $0.11 \pm 0.05$ & $0.16 \pm 0.04$ & $<0.0001$ \\
MUFAs & $9.45 \pm 1.32$ & $11.64 \pm 1.36$ &
\end{tabular}

Table 3- fatty acid profile of epicardial adipose tissue in diabetic and non-diabetic patients

\begin{tabular}{lccc}
\hline \multicolumn{1}{c}{ Variable } & $\begin{array}{c}\text { Non-diabetic (40 patients) } \\
\text { Mean } \pm \text { SD }\end{array}$ & $\begin{array}{c}\text { Diabetic (28 patients) } \\
\text { Mean } \pm \text { SD }\end{array}$ & p- Value \\
\hline Lauric acid (12:0) & $0.82 \pm 0.21$ & $0.87 \pm 0.22$ & 0.801 \\
Myristic acid (14:0) & $2.48 \pm 0.66$ & $2.68 \pm 0.63$ & 0.345 \\
Palmitic acid (16: 0) & $22.12 \pm 3.71$ & $22.70 \pm 4.12$ & 0.21 \\
Palmitoleic acid 16:1t & $1.41 \pm 0.32$ & $1.45 \pm 0.29$ & 0.639 \\
Palmitoleic acid 16:1n-7 & $7.42 \pm 1.64$ & $8.82 \pm 1.56$ & 0.033 \\
Stearic acid (18:0) & $2.64 \pm 0.64$ & $5.10 \pm 1.32$ & 0.003 \\
Oleic acid 18:1t & $4.54 \pm 0.86$ & $5.90 \pm 1.10$ & $<0.0001$ \\
Oleic acid 18:1n-9 & $39.24 \pm 4.84$ & $35.10 \pm 4.16$ & 0.311 \\
Oleic acid 18:1n-11 & $2.44 \pm 0.66$ & $1.60 \pm 0.48$ & 0.0001 \\
Linoleic acid 18:2t & $2.12 \pm 0.47$ & $2.96 \pm 0.52$ & 0.330 \\
Linoleic acid 18:2n-6 & $12.71 \pm 3.02$ & $10.54 \pm 1.91$ & 0.630 \\
Linoleic acid 18:3n-9 & $0.64 \pm 0.16$ & $0.50 \pm 0.12$ & 0.840 \\
Conjugated linoleic acid (CLA) & $1.08 \pm 0.24$ & $0.69 \pm 0.14$ & 0.033 \\
Arachidonic acid 20:4n-6 & $0.56 \pm 0.13$ & $0.25 \pm 0.07$ & 0.025 \\
Acid eicosapentaeonic 20:5n-3 & $0.16 \pm 0.03$ & $0.15 \pm 0.05$ & 0.015 \\
Docosahexaenoic acid 22:6n-3 & $0.18 \pm 0.04$ & $0.17 \pm 0.04$ & 0.0001 \\
\hline
\end{tabular}

There was a minor decrease in the saturated fatty acid 16: 0 content (Palmitic acid) of epicardial adipose tissue in diabetic patients compared to non-diabetics $(\mathrm{P}=0.21)$. There was a significant increase in FFA 18:0 and CLA of epicardial adipose tissue in diabetics $(\mathrm{P}=0.003)$ compared to those of controls, while there was a significant reduction in level of FFA $18: 1 \mathrm{n}-11 \quad(\mathrm{P}=0.0001)$. The content of arachidonic acid and its precursors (linoleic acid) in epicardial adipose tissue of the two groups did not differ significantly, but the level of epicardial omega-3 FFA (20:5n-3) $(\mathrm{P}=0.015)$ and $22: 6 \mathrm{n}-3(\mathrm{P}=0.0001)$ reduced significantly in these patients (Figure 1). 
Figure 1- Comparison of fatty acid profile of epicardial adipose tissue in diabetic and non-diabetic candidates for CABG. SFAs (saturated fatty acids), TFAs (trans-fatty acids), $\omega$-6FA (Omega-6 fatty acids), $\omega-3 F A$ (Omega-3 fatty acids)

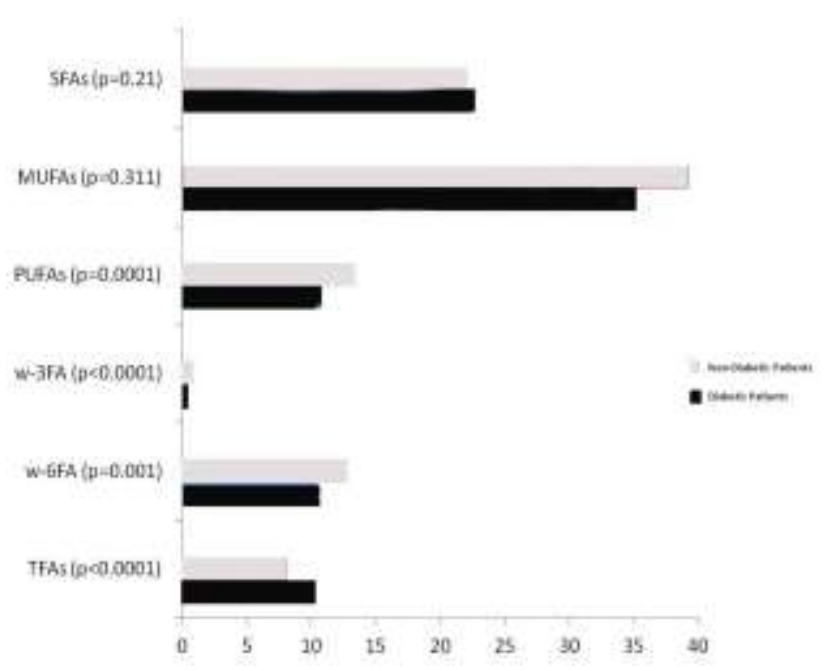

\section{DISCUSSION}

In this study, FFA profile of epicardial adipose tissue in diabetic and non-diabetic candidates for open-heart surgery was assessed and determined. Both groups were homogenized in terms of age, gender, weight, BMI and smoking habit. Despite the use of medication for glycemic control, blood glucose and glycosylated hemoglobin levels of diabetics differed significantly in comparison with the non-diabetics. This indicates that hypoglycemia was not controlled well in these patients. The triacylglycerol serum level was higher in diabetics, which indicates long-term high blood glucose levels in these patients. There was a significant increase in the level of saturated fatty acids (C12 and $\mathrm{C} 16)$, while a significant reduction was observed in the level of unsaturated fatty acids (20:4n-6) in serum fatty acids fraction of diabetic patients with severe cardiovascular stenosis who were candidates for Coronary artery bypass grafting (CABG). Since serum FFAs usually originate from adipose tissue and are less influenced by diet (16), they can be considered as suitable templates for fatty acids in adipose tissues of the entire body. Palmitic aid is normally one of the main saturated FFAs in the body. It has been reported that this fatty acid prevents proliferation of vascular smooth muscles and inhibits the formation of atherosclerotic plaques (17). Reduced serum levels of arachidonic acid in diabetics, further, manifests the role of palmitic acid in stimulating the pancreatic beta cells to secrete insulin (18). The exact reason for increased palmitic acid and decreased arachidonic acid levels in diabetic patients with CVD is not still clear. Increase in serum levels of palmitic acid and stearic acid, and decreased serum levels of 18: $1 \mathrm{n}-9$ in the phospholipid fraction of diabetic patients have been reported previously (19). In addition, a significant reduction in serum levels of 18: $2 n-6,20: 3 n-6$ and 18: $3 n-3$ among the PUFAs was reported in diabetic patients (20). The present study demonstrated a significant increase in serum levels of saturated FFAs and decrease in the levels of MUFAs, 18: $2 n-6$ and 18: $3 n-9$ in diabetic patients. The direct independent relationship between serum level of stearic acid and palmitic acid with incidence of diabetes has been reported (21), and according to scientific evidence, the first report was about the FFA content of type II diabetes mellitus patients. There was a difference between the profile of remaining FFA in phospholipids fraction of diabetic and nondiabetic patients undergoing CABG, which may be due to differences in patients' diet. In this regard, the relationship between FFA profile of plasma phospholipids and diet of patients was previously reported (22). 
In a study that assessed the risk of atherosclerosis in different populations, a solid relationship was demonstrated between the concentration of saturated fatty acids and unsaturated fatty acids in serum phospholipids fraction and type of diet (23). Generally, plasma MUFAs are androgenic and not influenced by diet. Thus, the reduction of serum MUFAs levels in the present study is possibly due to complications of diabetes. Since epicardial adipose tissue is very partial and limited, few studies have been conducted on variations of its FFA composition. The present study is almost the first to investigate the FFA changes in the epicardial adipose tissue of diabetic patients who are candidates for CABG. Changes in the composition of fatty acids in tissues of diabetic patients are mainly due to the impaired metabolism of fatty acids such as their uptake, movement and androgen synthesis (24). The results of this study showed a significant decrease in palmitic acid of the epicardial adipose tissue in diabetics. On the contrary, a significant increase in the level of fatty acid C18:0 was observed in the epicardial adipose tissue of these patients. The evidence suggest that palmitic acid prevents the development of atherosclerotic plaques by limiting the proliferation and migration of vascular smooth muscle cells (25), whereas stearic acid (18:0) have no potent biological activity in this regard (26). The level of epicardial adipose tissue metabolism and its metabolic exchange with vessel wall is much greater than in other adipose tissues (27). The results obtained in this study clearly show the role of diabetes on atherosclerotic changes of the epicardial tissue that confirms the findings of previous studies. A significant reduction in the level of 18:1n-11 in epicardial adipose tissue of diabetics was observed in the present study. It is proven that oleic acid unlike palmitic acid induces the formation and progression of atheroma by stimulating proliferation of vascular smooth muscle cells (28). The results also showed a significant reduction in the content of omega-3 (20: $5 n-3$ and 22: $6 n-3)$ and its precursor (18: $2 n-6)$ in the epicardial adipose tissue that was in agreement with the results of Hudson et al. study (29). The mentioned study reported a significant reduction in the level of docosahexaenoic acid in visceral tissue of patients with severe obesity. Arachidonic acid exerts its antidiabteic effects by stimulating insulin secretion from pancreatic beta cells (30). Moreover, the reduction of this fatty acid in arterial wall of diabetics has been reported (31) that corresponds with our results. However, a significant increase was observed in the level of CLA in epicardial adipose tissue of diabetic patients. The relationship between the level of trans-fatty acids and diet has not been yet reported. Thus, change in fatty acid profile of tissues is due to metabolic changes in patients with diabetes. It has been shown that the increased trans-fatty acids can clearly lead to progression of atherosclerosis (32). The results of this study are limited to diabetic patients with more than $75 \%$ vascular involvement who were candidates for CABG, and therefore cannot be generalized to all patients. Although both groups were homogenized in terms of race, age, gender and lipid profile (except triacylglycerols), the type of diet and control of hyperglycemia may have affected the obtained results. Therefore, individuals with high blood pressure, high blood cholesterol levels and high triacylglycerol patients were excluded from this study to better match the study groups.

\section{CONCLUSION}

Significant decreased level of fatty acids 16: 0 and omega-3 and elevated trans- and conjugated fatty acids in epicardial adipose tissue of diabetic patients compared to nondiabetics aggravate the risk of atheroma formation in the arteries.

\section{ACKNOWLEDGMENTS}

Hereby, the efforts of Shahid Madani Hospital operating room staff, Department of Biochemistry and Clinical laboratories of Tabriz University of Medical Sciences are gratefully acknowledged.

\section{CONFLICT OF INTEREST}

We warrant that the article is the Authors' original work. We warrant that the article has not received prior publication and is not under consideration for publication elsewhere. 


\section{REFERENCES}

1.Creager MA, Lüscher TF, Cosentino F, Beckman JA. Diabetes and Vascular Disease: Pathophysiology, Clinical Consequences, and Medical Therapy: Part I. Circulation. 2003;108: 1527-1532. doi: 10.1161/01.CIR.0000091257.27563.32.

2.Weyer C, Bogardus C, Mott DM, Pratley RE. The natural history of insulin secretory dysfunction and insulin resistance in the pathogenesis of type 2 diabetes mellitus. J Clin Invest. 1999; 104(6): 787-794.

3.Oprescu AI, Bikopoulos G, Naassan A, Allister AM, Tang C, Park E, et al. Free Fatty Acid-Induced Reduction in Glucose-Stimulated Insulin Secretion Evidence for a Role of Oxidative Stress In Vitro and In Vivo .Diabetes. 2007; 56(12): 2927-2937.

4. Zhao YF, Feng DD, Chen C. Contribution of adipocyte-derived factors to betacell dysfunction in diabetes. Int J Biochem Cell Biol. 2006; 38(5-6): 804819.

5.Nolan CJ, Madiraju MS, Delghingaro-Augusto V, Peyot ML, Prentki M. Fatty acid signaling in the betacell and insulin secretion. Diabetes. 2006; 55(2): S16$\mathrm{S} 23$.

6.Pilz S, Scharnagl H, Tiran B, Seelhorst U, Wellnitz B, Boehm BO, et al. Free fatty acids are independently associated with all-cause and cardiovascular mortality in subjects with coronary artery disease. J Clin Endocrinol Metab. 2006; 91(7): 2542-2547.

7.Blaak EE. Fatty acid metabolism in obesity and type 2 diabetes mellitus. Proc Nutr Soc. 2003; 62(3): 753-760.

8.Lavie CJ, Milani RV, Mehra MR, Ventura HO.

Omega-3 Polyunsaturated Fatty Acidsand

Cardiovascular Diseases. Journal of the American College of Cardiology. 2009; 54(7): 585-94.

9.Chien KL, Chao CL, Kuo CH, Lin HJ, Liu PH, Chen $\mathrm{PR}$, et al. Plasma fatty acids and the risk of metabolic syndrome in ethnic Chinese adults in Taiwan. Lipids in Health and Disease. 2011, 10: 33. doi: 10.1186/1476511X-10-33.

10. Shadid S, Koutsari C, Jensen MD. Direct free fatty acid uptake into human adipocytes in vivo: relation to body fat distribution. Diabetes. 2007, 56(5): 1369-1375. doi: $10.2337 / \mathrm{db} 06-1680$.

11. Zhao YF, Feng DD, Chen C. Contribution of adipocyte-derived factors to betacell dysfunction in diabetes. Int J Biochem Cell Biol. 2006, 38(5-6): 804819.

12. Greulich S, Maxhera B, Vandenplas G, de Wiza DH, Smiris K, Mueller $\mathrm{H}$, et al. Secretory products from epicardial adipose tissue of patients with type 2 diabetes mellitus induce cardiomyocyte dysfunction. Circulation. 2012; 126(19): 2324-34.

13.WHO. World Health Organization (2005) Obesity and Overweight. Available

at

http://www.euro.who.int/en/what-we-do/health-

topics/disease-prevention/nutrition/facts-and-figures

14. Bligh EG, Dyer WJ. Extraction of Lipids in Solution by the Method of Bligh \& Dyer. Can J Biochem Physiol. 1959; 37: 911-7.

15. Lepage G, Roy CC. Direct transesterification of all classes of lipids in a one-step reaction. J Lipid Res. 1986; 27(1): 114-20.
16. Yorgun H, Canpolat U, Hazırolan T, Ateş AH, Sunman H, Dural M, et al. Increased epicardial fat tissue is a marker of metabolic syndrome in adult patients. Int $\mathbf{J}$ Cardiol. 2013; 165(2): 308-13. doi: 10.1016/j.ijcard.2011.08.067.

17. Yerramasu A, Dey D, Venuraju S, Anand DV, Atwal $\mathrm{S}$, Corder $\mathrm{R}$, et al. Increased volume of epicardial fat is an independent risk factor for accelerated progression of subclinical coronary atherosclerosis. Atherosclerosis. 2012; 220(1): 223-30. doi: 10.1016/j.atherosclerosis.

18. Novgorodtseva TP, Karaman YK, Zhukova NV, Lobanova EG, Antonyuk MV, Kantur TA. Composition of fatty acids in plasma and erythrocytes and eicosanoids level in patients with metabolic syndrome. Lipids Health Dis, 2011, 10: 82-8. doi: 10.1186/1476-511X-10-82.

19. Korani M, Firoozrai M, Maleki J, Ghahramanpour F, Heidari I, Fallah S, Seifi M. Distribution of fatty acids in adipose tissue of patients with type 2 diabetes. Clin Lab. 2012; 58(5-6): 457-64.

20. Goldberg IJ. Diabetic Dyslipidemia: Causes and Consequences. J Clin Endocrinol Metab. 2001; 86(3): 965-71.

21. Ali AH, Koutsari C, Mundi M, Stegall MD, Heimbach JK, Taler SJ, et al. Free fatty acid storage in human visceral and subcutaneous adipose tissue: role of adipocyte proteins. Diabetes, 2011, 60(9): 2300-7. doi: $10.2337 / \mathrm{db} 11-0219$

22. Zhang Y, Liu C, Zhu L, Jiang X, Chen X, Qi X, et al. PGC-1alpha inhibits oleic acid induced proliferation and migration of rat vascular smooth muscle cells. PLoS One. 2007; 2(11): e1137.

23. Kien CL, Bunn JY, Ugrasbul F. Increasing dietary palmitic acid decreases fat oxidation and daily energy expenditure. Am J Clin Nutr. 2005; 82(2): 320-6.

24. Persaud SJ, Muller D, Belin VD, Kitsou-Mylona I, Asare- Anane H, Papadimitriou A, et al . The role of arachidonic acid and its metabolites in insulin secretion from human islets of langerhans. Diabetes. 2007; 56(1): 197-203.

25.Klein-Platat C, Drai J, Oujaa M, Schlienger JL, Simon C. Plasma fatty acid composition is associated with the metabolic syndrome and low-grade inflammation in overweight adolescents. Am J Clin Nutr. 2005; 82(6): 1178-84.

26. Wang L, Folsom AR, Zheng ZJ, Pankow JS, Eckfeldt JH. Plasma fatty acid composition and incidence of diabetes in middle-aged adults: the Atherosclerosis Risk in Communities (ARIC) Study. Am J Clin Nutr. 2003; 78(1): 91-8.

27. Hajer GR, van Haeften TW, Visseren FL. Adipose tissue dysfunction in obesity, diabetes, and vascular diseases. Eur Heart J. 2008; 29: 2959-71.

28. Ma J, Folsom AR, Shahar E, Eckfeldt JH. Plasma fatty acid composition as an indicator of habitual dietary fat intake in middle-aged adults. The Atherosclerosis Risk in Communities (ARIC) study Investigators. Am J Clin Nutr. 1995; 62(3): 564-71. its use as a biomarker of dietary intake. Prog Lipid Res. 2008; 47(5):348-80. doi: 10.1016/j.plipres.2008.03.003. 
29. Hodson L, Skeaff CM, Fielding BA. Fatty acid composition of adipose tissue and blood in humans and

30. Daubresse JC. Atherosclerosis and nutrition. Rev Med Brux. 2000; 21: A359-62.

31. Aas V, Hessvik NP, Wettergreen M, Hvammen AW, Hallén S, Thoresen $\mathrm{GH}$, et al. Chronic hyperglycemia reduces substrate oxidation and impairs metabolic switching of human myotubes. Biochim Biophys Acta.
2011; 1812(1): 94-105. doi: 10.1016/j.bbadis.2010.09.014.

32. Wang CP, Hsu HL, Hung WC, Yu TH, Chen YH, Chiu CA, et al. Increased epicardial adipose tissue (EAT) volume in type 2 diabetes mellitus and association with metabolic syndrome and severity of coronary atherosclerosis. Clin Endocrinol (Oxf). 2009; 70(6): 87682. doi: 10.1111/j.1365-2265.2008.03411.x. 